\title{
Morphological and Structural Study of Heat-Affected Zone Induced by Laser Cutting of Glassy Metal Tapes
}

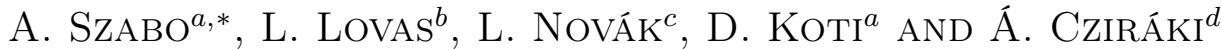 \\ ${ }^{a}$ University of Dunaujvaros, Institute of Engineering, Department of Mechanical Engineering, \\ Tancsics M. u. 1/A, 2400 Dunaujvaros, Hungary \\ ${ }^{b}$ Budapest University of Technology and Economics, Department of Automotive Technologies, \\ Stoczek J. u. 6, H-1111 Budapest, Hungary \\ ${ }^{c}$ Technical University of Kosice, Faculty of Electrical Engineering and Informatics, \\ Department of Physics, Komenského park 204120 Košice, Slovakia \\ ${ }^{d}$ Eötvös Loránd University, Department of Matrials Physics, \\ Pazmany Peter setany 1/a., 1117 Budapest, Hungary
}

\begin{abstract}
The promising properties of glassy alloys are the low coercive force and the low core loss. Although, the Fe-based amorphous ribbons are excellent in this respect, several additional requirements have to be satisfied, like the shaping of this soft magnetic tapes into the appropriate forms, and simultaneously avoiding the degradation (local crystallization) of the individual glassy elements. In this article the results of laser cutting experiments is reported. This cutting process causes local degradation, which is known as the "heat affected layer". This layer appears as a visible parallel zone with the cutting front in the micrograph. The thickness of this front depends on several parameters of cutting procedure (power density of beam and scanning rate or the flow rate of applied working gas). In this paper the fine structure of the heat affected zone is investigated. The high resolution pictures shows a columnar microstructure of the heat affected layer, resembling a typical re-solidified microstructure. The dimension of columnar structure changes drastically according to the requirements of unidirectional heat conduction. The magnitude of heat affected zone will be correlated with the soft magnetic properties of the samples.

DOI: 10.12693/APhysPolA.137.1006
\end{abstract}

PACS/topics: laser cutting, glassy alloy, mechanical properties, magnetic properties

\section{Introduction}

Recently an attempt was made to apply the soft magnetic glassy tapes to build stator and rotor elements for electric motors. The reason is the potential increase of electric motor efficiency. Based on [1, 2], the Fe-based glassy alloys are candidates for this purpose, partially due to their sufficient soft magnetic properties, and partially because of the well developed technology directed to the production of wide $(\sim 200 \mathrm{~mm})$ amorphous tapes. Several additional tasks have to be solved before in order to use the glassy tapes either as stator elements, such as the shaping (cutting) the tapes to a desired form. In this paper some results connected with the laser cutting is reported [3]. Morphological and structural changes, caused by the laser cutting, are studied using traditional optical, and high resolution (scanning electron microscopy) technique, as well as local X-ray phase analyses. The structural information are fitted to the magnetic measurements.

\section{Experimental}

The samples for magnetic measurements are cut from the METGLAS tapes in the form of $100 \mathrm{~mm}$ long,

\footnotetext{
*corresponding author; e-mail: szaboattila@uniduna.hu
}

$10 \mathrm{~mm}$ wide, and $30 \mu \mathrm{m}$ thick stripes. The laser cutting process were performed on A Oerlikon OPL 2000 type $\mathrm{CO}_{2}$ laser in continuous radiation mode, with the power of $50 \mathrm{~W}$ and $0.27 \mathrm{~mm}$ spot diameter. The cutting speed (i.e., the movement speed of the CNC board) was set between $1000 \mathrm{~mm} / \mathrm{min}$ and $4000 \mathrm{~mm} / \mathrm{min}$. The thickness of heat affected zone was determined subsequently after the cutting process. For the micro-hardness and optical measurements CSM Micro Combi Tester was used and Zeiss Axio Observer Z1M optical microscope was used for the morphological study of heat affected zone.

For the high resolution measurements Zeiss EVO MA 15 type scanning electron microscope was applied. The magnetic measurements were performed in astatic magnetometer (coercive force $\left(H_{c}\right)$, anisotropy $\left(K_{\sigma}\right.$ and $\left.K_{i}\right)$, were determined from the magnetization curves).

\section{Results and discussion}

The laser cutting is based on the local melting of material [4]. The cutting line (thin, locally molten layer) is formed via the line scanning of laser beam over the sample (see Fig. 1). The actual power density depends primarily on the applied energy density of laser beam, on the scanning rate, and also depends on the properties and flow rate of the working gas [5], the role of which is to remove the molten metal (alloy) layer from cutting 


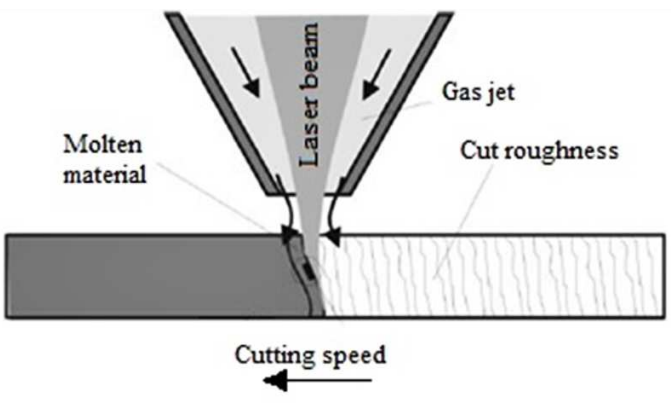

Fig. 1. The mechanism of laser cutting (side view).

gap. As a consequence of this unidirectional, impulse-like local heating, high thermal gradient is developed inside the neighbouring layer of sample together with pulse-like heat conduction in the plan of $30 \mu \mathrm{m}$ thick glassy tape, resulting either phase transformation (crystallization) or structural relaxation [6]. The transformed region reins parallel to the cutting age which is denominated as "heat affected" zone.

As shown in Fig. 2 and 3, the difference between the optical reflectivity of the heat affected area and the intact part of ribbon is obvious. This is the reason of contrast between the two part of surface area, hence chemical etching is not necessary for the detection of structural change. The scanning rate dependence of thickness of transformed zone is obvious when Fig. 2 and 3 are compared. The reason is the difference in the magnitude of local heat evolution associated with the cutting, which is essentially pulse-like temperature increase, being proportional with the "pulse length". This observation is similar to the phenomena associated with that observed during the current-pulse treatments of glassy alloys [6]. However, the HAZ itself is structurally inhomogeneous, which is especially clear from Fig. 2, where the thickness is about $200 \mu \mathrm{m}$.

\subsection{The fine structure of $H A Z$}

Figure 4 shows a high resolution picture from the immediate vicinity of cutting line (electron micrograph). Typical columnar solidified structure is shown, with the structure resembling to the solidified eutectics (ledeburite) in Fe-C melts (or the bainite, formed during the decomposition of austenite in carbon steels) (Fig. 4). The high resolution picture is obtained by scanning electron microscope. The double- phase columnar structure coarse near the surface (cutting line), where the local temperature is higher, shows increasingly finer dispersity along the temperature gradient in the deeper region of HAZ.

This structure hints directly at the existence of unidirectional heat conduction from the cutting line into the inner part of the tape. Around the interface between the transformed (crystallized) layer and the intact (untransformed) part of ribbon the peak of pulselike heat-shock should be around the initial temperature of crystallization of METGLAS (about $500^{\circ} \mathrm{C}$ ).

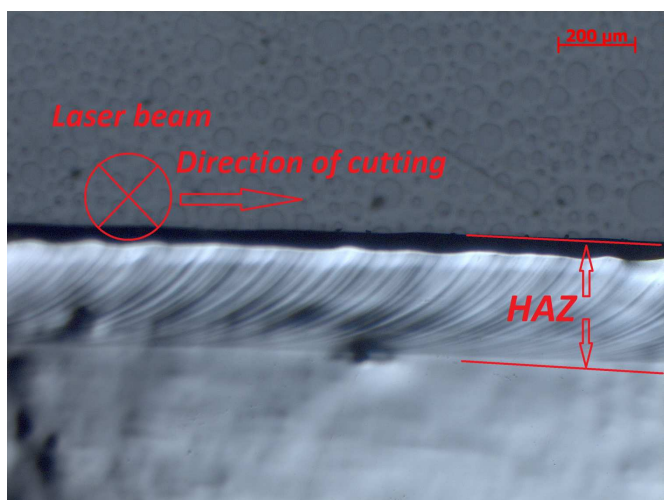

Fig. 2. Optical micrographs of the heat affected zone after the laser cutting of METGLAS tapes the applied scanning rates of $4000 \mathrm{~mm} / \mathrm{min}$ (plan view).

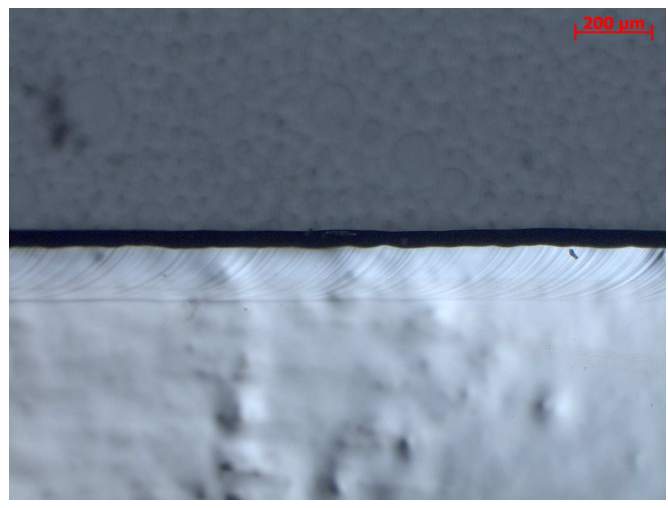

Fig. 3. Optical micrographs of the heat affected zone after the laser cutting of METGLAS tapes the applied scanning rates of $1000 \mathrm{~mm} / \mathrm{min}$ (plan view).

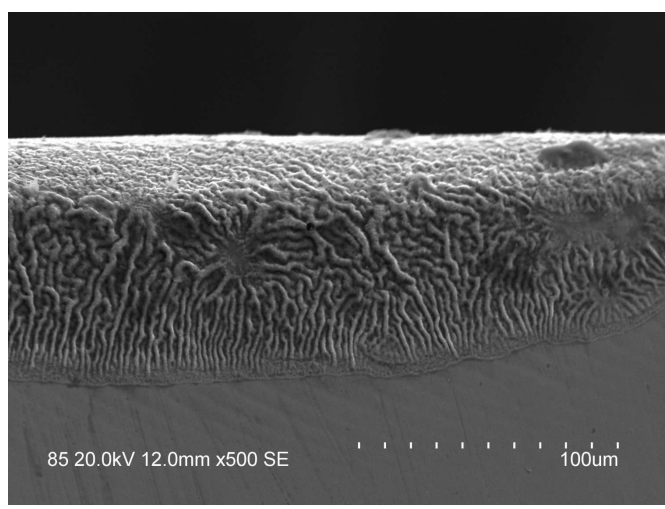

Fig. 4. Resolidified layer structure in the vicinity cutting line obtained from scanning electron microscope (plan view).

\subsection{Local hardening and brittleness increase in the heat affected zone}

It is well known, that (mainly in the TM-Metalloid type glasses) the hardness increases during structural relaxation and especially due to simultaneous crystallization, the samples becomes brittle [7]. Therefore, 


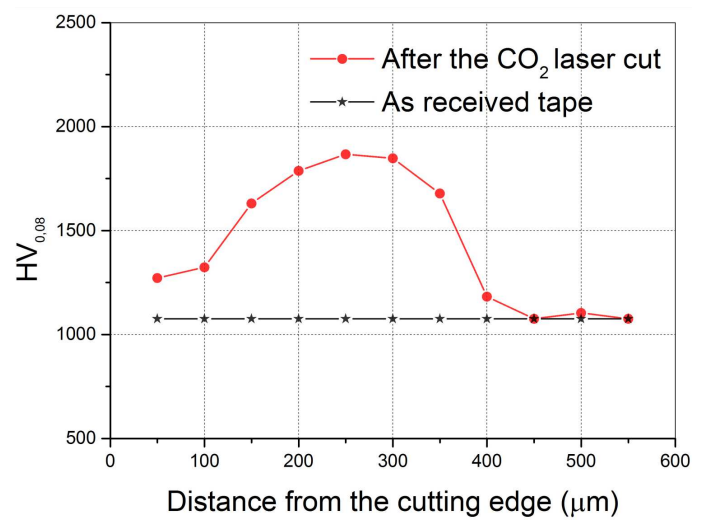

Fig. 5. Typical results of $\mathrm{HV}$ measurements within the HAZ.

it is expected that hardness increase can be experienced within the HAZ. The resulting tendency isplotted in Fig. 5. It is obvious, that $\mathrm{HV}$ gradually increases within the heat-affected zone indicating the physically inhomogeneous nature of HAZ. Presumably the coexistence of structurally relaxed and the completely crystallized areas are responsible for the considerable HV fluctuation within the HAZ.

\subsection{Structural investigation of heat affected zone}

Local electrolytic thinning of tapes near the cutting line reveals the high resolution structure of heat affected zone, including the phase-identification in the transformed region, by applying electron diffraction pattern. Structurally, two crystalline phase was identified. Near the cutting line $\mathrm{Fe}_{3}(\mathrm{Si}, \mathrm{B})$ crystalline grains with typically 100-150 nm sizes could be detected, while smaller dispersed grains with $\mathrm{Fe}_{2} \mathrm{~B}$ structure was identified. These two phases were also identified in the DSC sample after the complete crystallization.

\subsection{The influence of $\mathrm{CO}_{2}$ laser cutting on the global soft magnetic properties}

The complete magnetization curves were measured in astatic magnetometer on samples with identical shape of $10 \mathrm{~mm}$ (wide) $\times 100 \mathrm{~mm}$ (long). To give the required shape for the astatic magnetometer, the samples were cut mechanically and $\mathrm{CO}_{2}$ laser was applied, as described in the experimental part. It was found that $H_{c}$ measured on $\mathrm{CO}_{2}$ cut samples with the measured value of $6.86 \mathrm{~A} / \mathrm{m}$ are significantly higher than that for the mechanically cut ones $(4.08 \mathrm{~A} / \mathrm{m})$. A significant increase was also found in the effective anisotropy constant $\left(K_{\text {eff }}\right)$. For $\mathrm{CO}_{2}$ laser cut the average value was $2830 \mathrm{~J} / \mathrm{m}^{3}$, while for mechanical cut it was $740 \mathrm{~J} / \mathrm{m}^{3}$. It is important to note that no significant difference can be detected between the samples cut parallel, or rectangular from the as-received tapes (longitudinal or rectangular with the casting direction applied during the production), which hints at the physical homogeneity of the samples over the whole area of tapes.

\section{Summary}

The morphological character and structure of the transformed region was investigated in soft magnetic glassy tapes after $\mathrm{CO}_{2}$ cutting using traditional optical microscopy and high resolution (electron microscopic), as well as X-ray diffraction techniques.

The high resolution pictures show a columnar microstructure within the HAZ, resembling typical resolidified microstructure. The dimension of columnar changes drastically alters, according to the unidirectional heat conduction. The local crystallization within the HAZ was detected by local microhardness measurements. The magnitude of HAZ was correlated with the changes in the global soft magnetic properties of the samples. When the width of $\mathrm{HAZ}$ exceeded $200 \mu \mathrm{m}$ during the $\mathrm{CO}_{2}$ lasercutting, $H_{c}$ increase and detectable decrease of saturation moment was found.

\section{Acknowledgments}

The research presented in this paper was carried out as part of the EFOP-3.6.2-16-2017-00016 project in the framework of the New Széchenyi Plan. The completion of this project is funded by the European Union and co-financed by the European Social Fund.

\section{References}

[1] A. Makino, A. Inoue, T. Masumoto, Mater. Trans. 36, 924 (1995).

[2] K.Q. Qiu, H.F. Zhang, A.M. Wang, B.Z. Ding, Z.Q. Hu, Acta Mater. 50 (14), 3567 (2002).

[3] J.M. Glass, H.P. Groger, R.J. Churchill, E.M. Norin, J. Mater. Eng. 12(1), 59 (1990).

[4] K. Bán, M. Nagy, A. Cziráki, Zs. Fogarassy, Dunakavics, VI, 17 (2018).

[5] A.L. Greer, in: Rapidly solidified alloys, Eds. H. Liebermann, Marcel Dekker Inc., 1993, p. 269.

[6] J. Kovac, L. Novák, L. Hubac, J. of Electr. Eng. 66 (7), 142 (2015).

[7] Z. Weltsch, K Klam, A. Lovas, Acta Phys. Pol. A 131, 669 (2017). 